\title{
Laminated, Composite and Sandwich Membranes Based on Graphene- Oxide with Nano-Textiles
}

Petra Roupcova $^{1,2 *}$, Karel Klouda1,2, Lucie Gembalova ${ }^{2}$, Eva Kuzelova-Kostalova ${ }^{3}$ and Jiri Chvojka ${ }^{3}$

${ }^{1}$ Research Institute for Occupational Health and Safety, Jeruzalemska 1283/9, Praha, 110 00, Czech Republic

${ }^{2}$ VSB-Technical University of Ostrava, Lumirova 13, Ostrava, 700 30, Czech Republic

${ }^{3}$ Technical University of Liberec, Studentska Liberec 1402/2, Liberec, 46117, Czech Republic

\begin{abstract}
The contribution describes preparation of graphene-oxide suspensions and their hybrid compounds, GO-biochar, $\mathrm{GO}-\mathrm{C}_{60}, \mathrm{GO}-\mathrm{CF}_{0.9}$, which are subsequently applied to nano-textiles using various techniques. This method was used to prepare composite and sandwich-type films or laminated nano-textiles. Relative arrangement in product (film) crosssections was identified in products prepared using SEM analysis. Thermal stability of the products was determined using DTA, DSC analysis and compared to the stability of the nano-textiles. Chemical properties of graphene- oxide (GO) allow a number of its modifications, partial reduction, creation of composites with metals and their oxides. Preparation and thermal analysis $\mathrm{GO}-\mathrm{TiO}_{2} / \mathrm{PCl} / \mathrm{GO}-\mathrm{TiO}_{2}$ has been described as an example. The conclusion of the project suggests possible application of the products (films).
\end{abstract}

Keywords: Nano-Textiles; Composite; Graphene

\section{Introduction}

GO membranes have laminar, layered structure with functional oxygenous epoxy, carboxyl, carbonyl or hydroxide groups, which induce the hydrophilic character of $\mathrm{sp}^{3} \mathrm{C}-\mathrm{O}$ (approx. 40\%), while also containing the hydrophobic component $\mathrm{sp}^{2} \mathrm{C}=\mathrm{O}[1]$.

There are possibilities of preparation for these membranes [1] such as smearing a drop of $\mathrm{GO}$ colloidal suspension over a smooth surface $\left(\mathrm{SiO}_{2}\right.$, polymer, paper etc.) via spray, vacuum filtering or the LangmuirBlodgett method. GO membranes can only exist as a free-standing $\mathrm{C}$-frame deposited either onto a different membrane and functionally connected with a polymer or modified into an "in situ" polymer matrix, creating a non-covalent or covalent composite connection [2-5], or onto a porous material [6-9].

Up until a certain level, the GO oxygenous functional group can be de-oxidized depending on the used reducing agent, preparing a compound that is commonly known in literature as $\mathrm{rGO}$. This compound has increased thermal stability, hydrophobic character and increased capability of $\pi-\pi$ interactions and defect (pore) creation within the carbonaceous grid frame. Graphene itself is a mono-atomic layer of carbon, undissolvable for any gases or solutions, while GO $(\mathrm{rGO})$ with controlled defects exhibits great potential for application in filtering technology. For graphene, pores are purposefully created in the C-grid using directed electron rays, ion oxidization etching or oxygenous plasma. Pore size and acquired shape are published in the graphic concept $[5,10]$. Pore size and shape subsequently influence the application in Figure 1 [11], which shows the different progression of gas/ion separation for GO and graphene. Membranes based on graphene, GO, rGO are applied in the area of molecular separation, both in selective separation of gases, ions, small and ultra-small particles, desalination and purification of water, including disinfection $[4,6,7,12-$ 17].

The results of gas and ion separation are influenced by diffusion speed [18], layer investing [19], spacing between nano-particles of GO providing channels (Figure 1), gap size between the layers. The functional groups also expand separation abilities and possibilities. Examples of selective separation: $\mathrm{CH}_{4} / \mathrm{CO}_{2}, \mathrm{CH}_{4} / \mathrm{H}_{2} \mathrm{~S}, \mathrm{CH}_{4} / \mathrm{N}_{2}, \mathrm{H}_{2} / \mathrm{CO}_{2}$

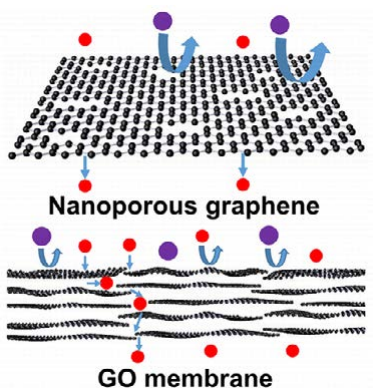

Figure 1: The porous membrane and the graphene stacked arrangement of G0 membrane.

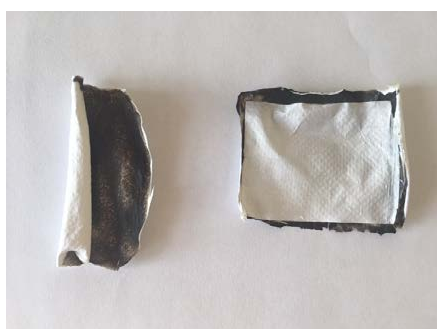

Figure 2: a) lamination and nanotextiles, b) composite.

*Corresponding author: Petra Roupcova, Research Institute for Occupational Health and Safety, Jeruzalemska 1283/9, Praha, 110 00, Czech Republic, Tel: 420774599992; E-mail: petra.roupcova@vsb.cz

Received: October 11, 2018; Accepted: October 22, 2018; Published: October 25 2018

Citation: Roupcova P, Klouda K, Gembalova L, Kuzelova-Kostalova E, Chvojka J (2018) Laminated, Composite and Sandwich Membranes Based on GrapheneOxide with Nano-Textiles. J Nanomed Nanotechnol 9: 517 doi: 10.4172/2157 7439.1000517

Copyright: ( 2018 Roupcova P, et al. This is an open-access article distributed under the terms of the Creative Commons Attribution License, which permits unrestricted use, distribution, and reproduction in any medium, provided the original author and source are credited. 
[9,20-23]. Graphene-based films have been finding application thanks to their filtering capabilities, as well as other application as adsorption materials, battery electrodes, super-capacitors, photo-catalysis, antibacterial materials and moisture sensors, organic and biological substances. Some of the application will be tested in the experimental part conc. adsorptive capabilities of GO, biochar and GO-Biochar films.

\section{Experimental Part}

GO is acquired by means of Hummers graphite oxidization (1958), e.g. via oxidation mixture of $\mathrm{KMnO}_{4}+\mathrm{NaNO}_{3}+\mathrm{H}_{2} \mathrm{SO}_{4}$. Once the mixture is dissolved using water, $\mathrm{HCl}$ and $30 \% \mathrm{H}_{2} \mathrm{O}_{2}$ solution, repeated decanting and skimming yields a water suspension with negative reaction to sulphate ions. By regulating the skimming time and speed, a certain consistency of the suspension can be achieved, which allows for variants when applying onto nano-textiles (see below).

The same procedure was used to oxidize graphite together with $\mathrm{C}_{60}$, $\mathrm{CF}_{0.9}$ fluorine-graphite and post-biomass pyrolysis compounds -biochar in various mass ratios, most often 2:1 in favour of graphite. This led to creation of hybrid compounds of $\mathrm{GO}-\mathrm{C}_{60}, \mathrm{GO}-\mathrm{CF}, \mathrm{GO}$ -biochar, which were able to create a film, membrane. These prepared suspensions of hybrid compounds and GO were applied onto the nano-textiles using a spatula, mechanical smearing or aerosol dispersion. Depending on the suspension consistency, this resulted in lamellar/composite arrangement (nano-textiles between GO layers) or a sandwich arrangement, i.e. layer alternation (nano-textile-GO-nanotextile) -see the illustrative in Figure 2. This allows for a wide range of variants, e.g. application of another GO layer, alternating nano-textile types. Further variation is provided by changing the level of meshing of the nanofibers in the nano-textiles. This also influences the level of adsorption on the surface or permeation through the textile. This is always followed up by drying at a temperature gradually increasing from 25 to $70^{\circ} \mathrm{C}$. For application in photo-catalysis, composite of GO$\mathrm{TiO}_{2} / \mathrm{PCL} / \mathrm{GO}-\mathrm{TiO}_{2}$ was also created, along with a sandwich where steel micro-fibers were inserted into the GO suspension with the goal of getting a film capable of shielding against magnetic radiation.

\section{Graphite oxidization- GO preparation}

$3 \mathrm{~g}$ of graphite have been re-layered in the Erlenmeyer flask using 65 $\mathrm{ml}$ of concentrated $\mathrm{H}_{2} \mathrm{SO}_{4}$ with $4 \mathrm{~g}$ of $\mathrm{NaNO}_{3}$ added. The mixture was stirred using a magnetic stirrer and cooled down to $7-10^{\circ} \mathrm{C}$. Afterwards $7 \mathrm{~g}$ of $\mathrm{KMnO}_{4}$ was gradually added and the mixture was gradually heated up to laboratory temperature, which was gradually increased to $50-66^{\circ} \mathrm{C}$. At this temperature, the condensing reaction mixture was stirred for 4 hours. The mixture was then left overnight at laboratory temperature, followed by adding $40 \mathrm{ml} \mathrm{HCl}$ and $40 \mathrm{ml} \mathrm{30 \%} \mathrm{H}_{2} \mathrm{O}_{2}$ into the flask and stirring the mixture for 1 hour. This was followed by decomposition (reaction) and final addition of $150 \mathrm{ml}$ of distilled water. The mixture was skimmed and the acidic water part decanted. As a final step, $100 \mathrm{ml}$ more of distilled water was added. This process was repeated 20 times until a negative reaction to sulphate ions was achieved.

\section{Oxidization of graphite and biochar}

$1.22 \mathrm{~g}$ of biochar and $1.7 \mathrm{~g}$ of graphite have been re-layered in the Erlenmeyer flask using $40 \mathrm{ml}$ of $\mathrm{H}_{2} \mathrm{SO}_{4}$ with $20 \mathrm{ml}$ of $\mathrm{HNO}_{3}$. The mixture was cooled down to $7-10^{\circ} \mathrm{C}$ (stirred using a magnetic stirrer). $20 \mathrm{~g}$ of $\mathrm{KClO}_{3}$ was then gradually added during intense stirring. The mixture was gradually heated up to laboratory temperature, which was gradually increased to $50-60^{\circ} \mathrm{C}$. At this temperature, the mixture was subjected to intense stirring for 4 hours. The resulting reaction mixture was left for 4 days at laboratory temperature. $100 \mathrm{ml}$ of distilled water, $40 \mathrm{ml}$ of $\mathrm{HCl}$ and $40 \mathrm{ml}$ of $\mathrm{H}_{2} \mathrm{O}$ was then added. The prepared acidic mixture was skimmed and the acidic water portion was decanted. Another $100 \mathrm{ml}$ of distilled water was added and the skimming and decanting process was repeated 20 times until a negative reaction to sulphate ions was achieved. The processes were performed at the same reaction conditions as for biochar, also for $\mathrm{C}_{60}, \mathrm{CF}_{0.9}$.

\section{GO-TiO2 composite}

$44 \mathrm{mg}$ of nano $\mathrm{TiO}_{2}$ was added into the Erlenmeyer flask with $8 \mathrm{ml}$ of dense suspension of GO. The mixture was alternately sonified and stirred. The content of the flask had become denser (a brown, mushy matter), so much that it was necessary to add $40 \mathrm{ml}$ of $\mathrm{H}_{2} \mathrm{O}$ and stir and sonify at $40^{\circ} \mathrm{C}$ for 4 hours. Once cooled, the suspension was applied onto PCL nano-textiles. The prepared films were gradually dried at $25-70^{\circ} \mathrm{C}$ for 16 hours.<smiles>CC(C)(C)CCCCOC(C)(C)C</smiles>

Steel micro-fibres (provided by the Technical University in Liberec)

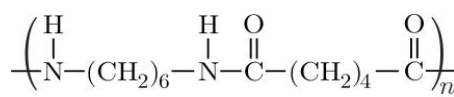

$$
\begin{aligned}
& \text { Nylon } 66 \\
& \left(\begin{array}{ll}
\mathrm{H} & \mathrm{O} \\
\mathrm{I} & \mathrm{I} \\
\mathrm{N} & -\left(\mathrm{CH}_{2}\right)_{5}-\mathrm{C}
\end{array}\right)_{n} \\
& \text { Nylon } 6
\end{aligned}
$$

Polymer nanofibers were prepared at the Technical University in Liberec using the "Nanospider" technology. These fibers were applied onto the polypropylene surface within the nano-textile mold.

Used chemical compounds -nano $\mathrm{TiO}_{2}$ made by Sigma Aldrych, biochar -biomass pyrolysis product (Biouhel.cz s.r.o., Zlín) $\mathrm{C}_{14} \mathrm{O}, 2 \%$ soiled by salts of $\mathrm{Si}, \mathrm{Al}, \mathrm{K}, \mathrm{Ca}, \mathrm{Mg}$.

\section{Device equipment}

SEM analysis: FEI Quanta 650 FEG scanning electron microscope (FEI, USA)

\section{TGA /DSC, 2 Metter Toledo}

\section{Results and Discussion}

As already stated in the experimental section, the described procedure enables a variety of modifications in the combination of GO and its hybrid compounds with nano-textiles, depending on the method by which the suspension is applied, its consistency and type and structure of nanofibers in the applied nano-textile. The procedure allows mechanical modifications (steel fibers together with GO between layers of PCL) and chemical modifications $\left(\mathrm{nTiO}_{2}\right)$. The size of the applied layers of GO and its hybrids was monitored via change of mass, including a following re-calculation to the area unit of the nanotextile or cut thickness (Figures 3-9). SEM images were not taken for sections of the pure nano- textiles (PCl, PA6) only in the case of hybrid modification. In addition to the SEM analysis, TGA and DSC analyses were used to determine the thermal stability in order to provide application safety. 
Citation: Roupcova P, Klouda K, Gembalova L, Kuzelova-Kostalova E, Chvojka J (2018) Laminated, Composite and Sandwich Membranes Based on Graphene-Oxide with Nano-Textiles. J Nanomed Nanotechnol 9: 517. doi: 10.4172/2157-7439.1000517

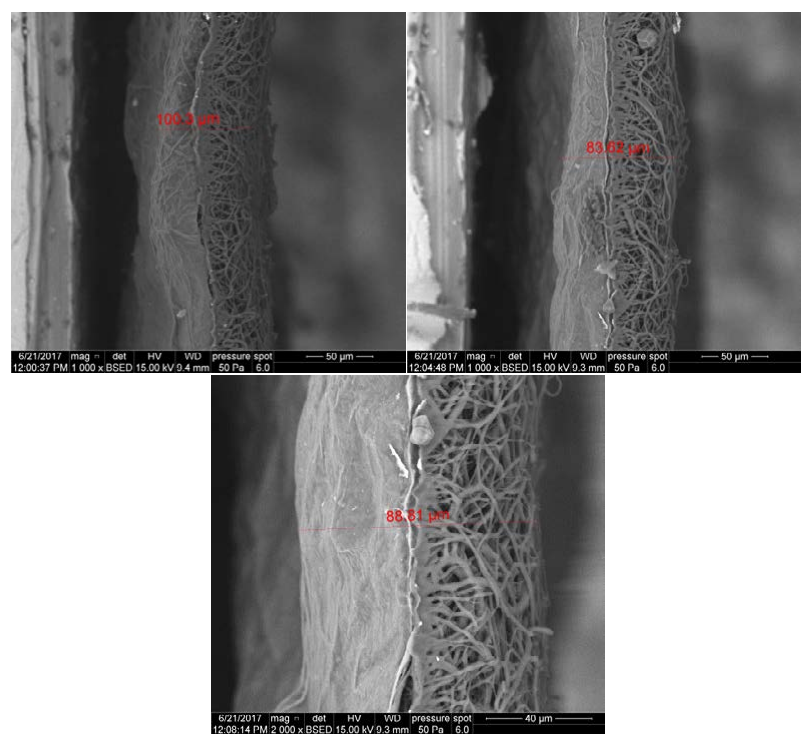

Figure 3: Sections of PCL nano-textile contact with GO applied (nanotextile lamination).

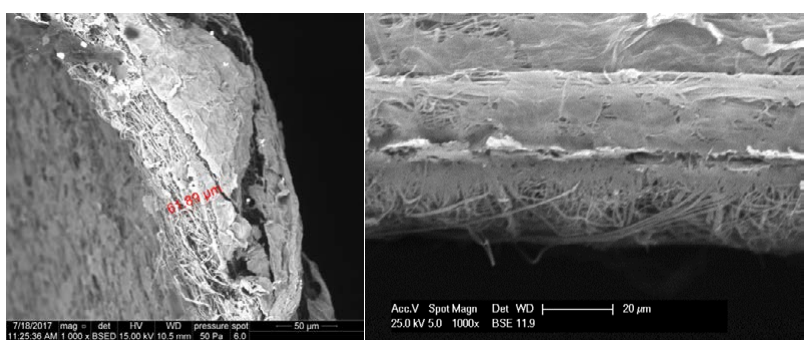

Figure 4: Section and structure of product surface I (PA6/GO/PA6) sandwich.

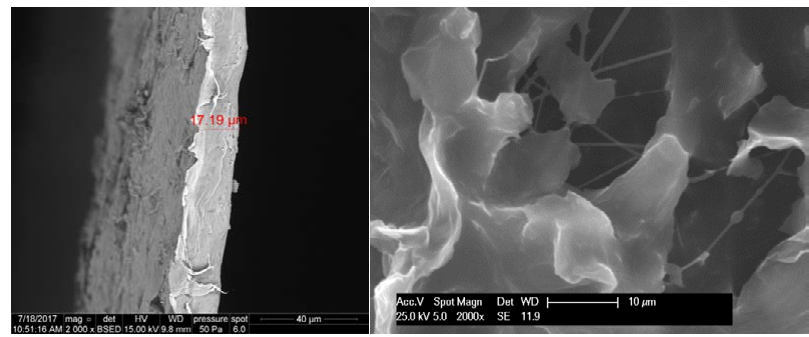

Figure 5: Section and structure of product II (GO-biochar/PCL/GObiochar) - composite.

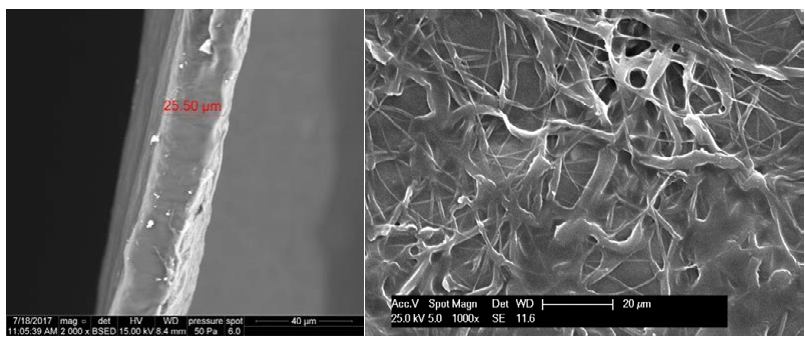

Figure 6: Section and structure of product surface IIII (GO/PCL/GO).

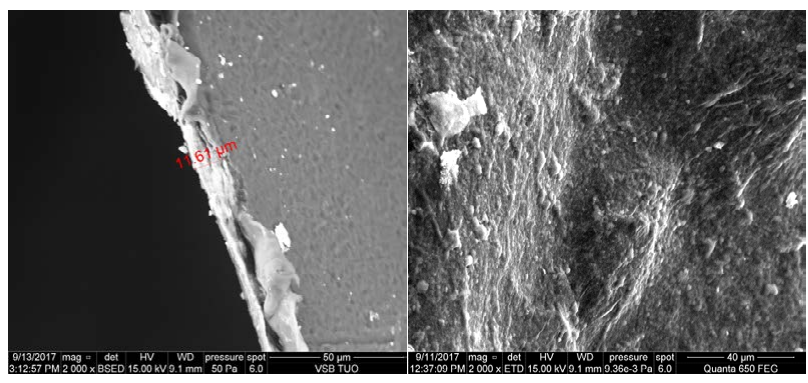

Figure 7: Section and structure of $1 \mathrm{GO}-\mathrm{TiO}_{2} / \mathrm{PCL} / \mathrm{GO}-\mathrm{TiO}_{2}$ surfacecomposite.

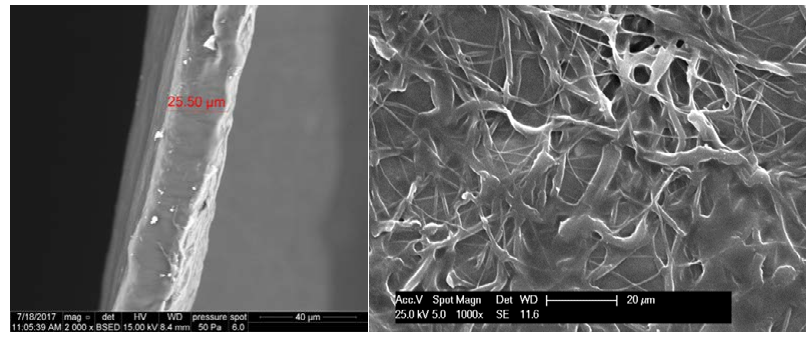

Figure 8: Section and structure of product surface IIII (GO/PCL/GO).

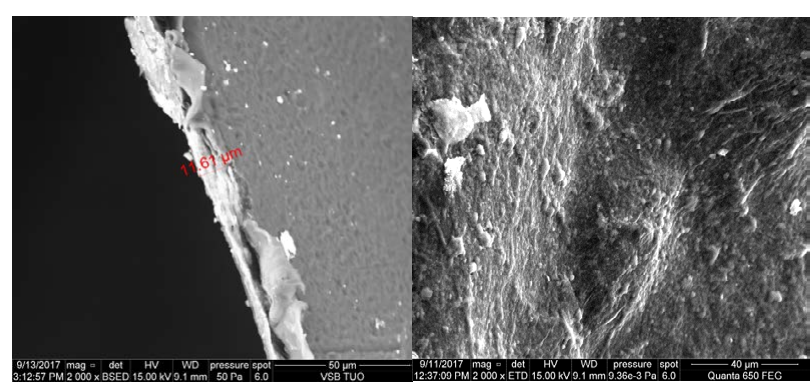

Figure 9: Section and structure of $\mathrm{GO}-\mathrm{TiO}_{2} / \mathrm{PCL} / \mathrm{GO}-\mathrm{TiO}_{2}$ surfacecomposite.

The next section shows pictures of sections and surfaces of selected film. The important property here is thermal resistance, which is presented by the TGA and DSC analysis curves.

\section{Thermal analysis of default precursors}

Thermal Analysis of precursors has been described through the Graph from Figures 10-13.

\section{Thermal analysis result comparison -PA6/GO/PA6 sandwich against PA6 nano-textile (I)}

Note the decomposition progression for the sandwich in Figure 14, where exo-effects are evenly alternated by endo-effect at temperatures from $150^{\circ} \mathrm{C}$ upwards, with the highest weight loss throughout the endo-effect progression. The entire sandwich decomposition ends in an exo-effect, peaking at $567^{\circ} \mathrm{C}$ with weight loss of $25 \%$.

The decomposition of the PA6 nano-textile itself takes place from $150^{\circ} \mathrm{C}$ to $285^{\circ} \mathrm{C}$ in a protracted endo-effect and a $23 \%$ weight loss. The greatest weight loss ( $39 \%$ ) also occurs during an endo-effect at $430^{\circ} \mathrm{C}$. There are two endo-effects on the curve Figure 12 , the first one at $384^{\circ} \mathrm{C}$ with a $6 \%$ weight loss and the second one with main maximum at $515^{\circ} \mathrm{C}$ and weight loss of $19 \%$. The GO influence manifested in warmer change 


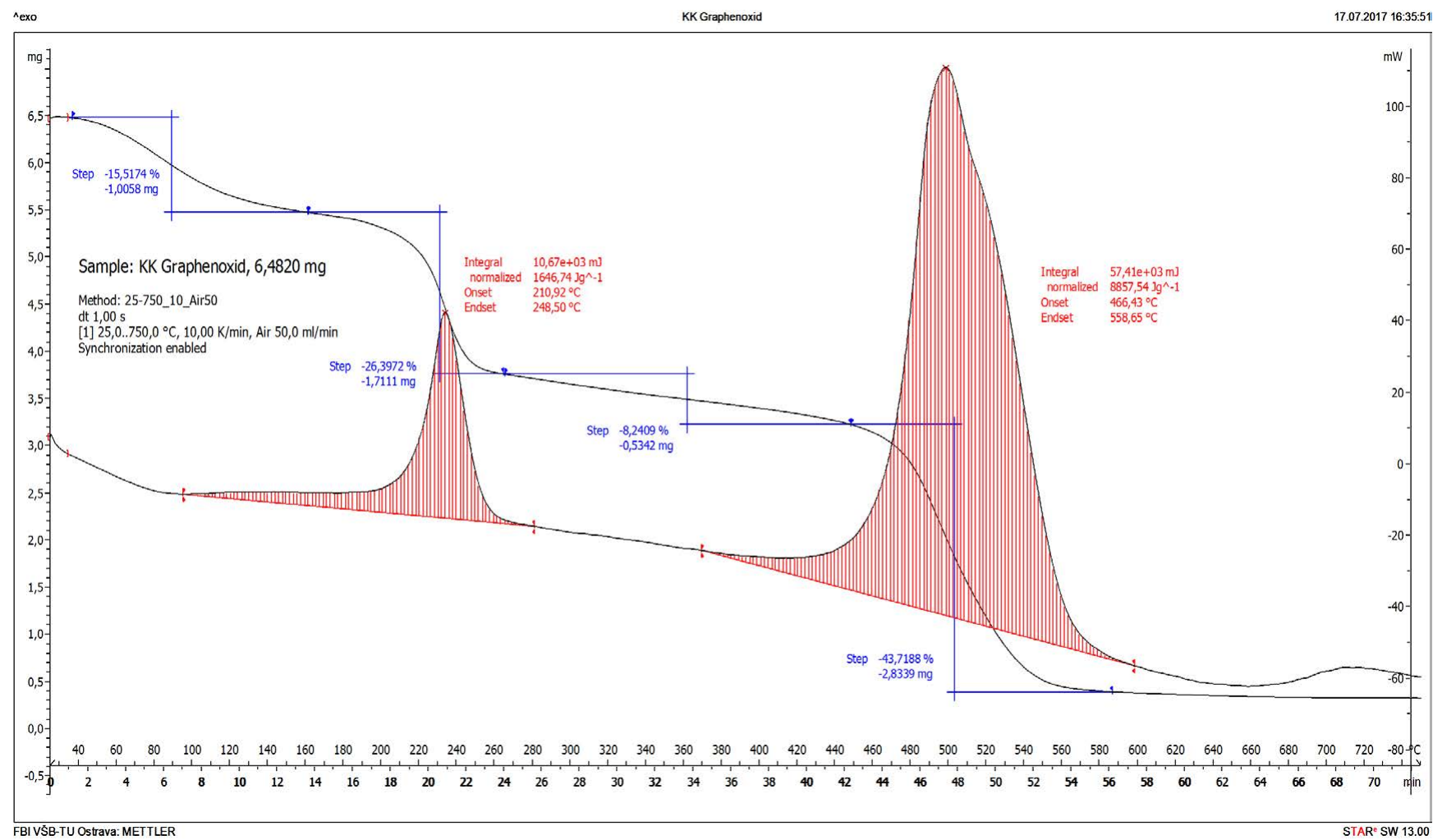

Figure 10: TGA and DSC analysis of GO.

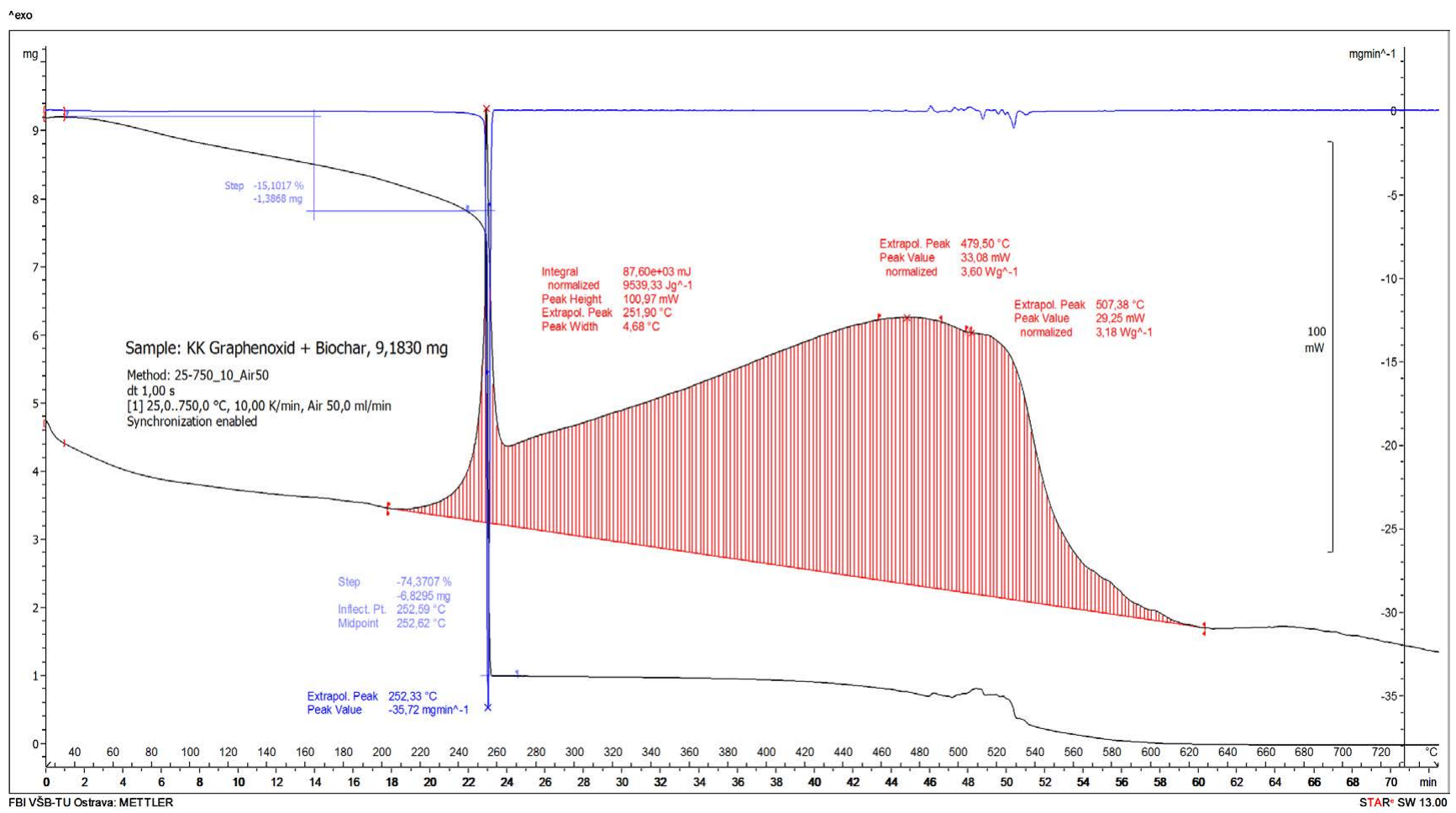

Figure 11: TGA and DSC analysis of GO-biochar. 


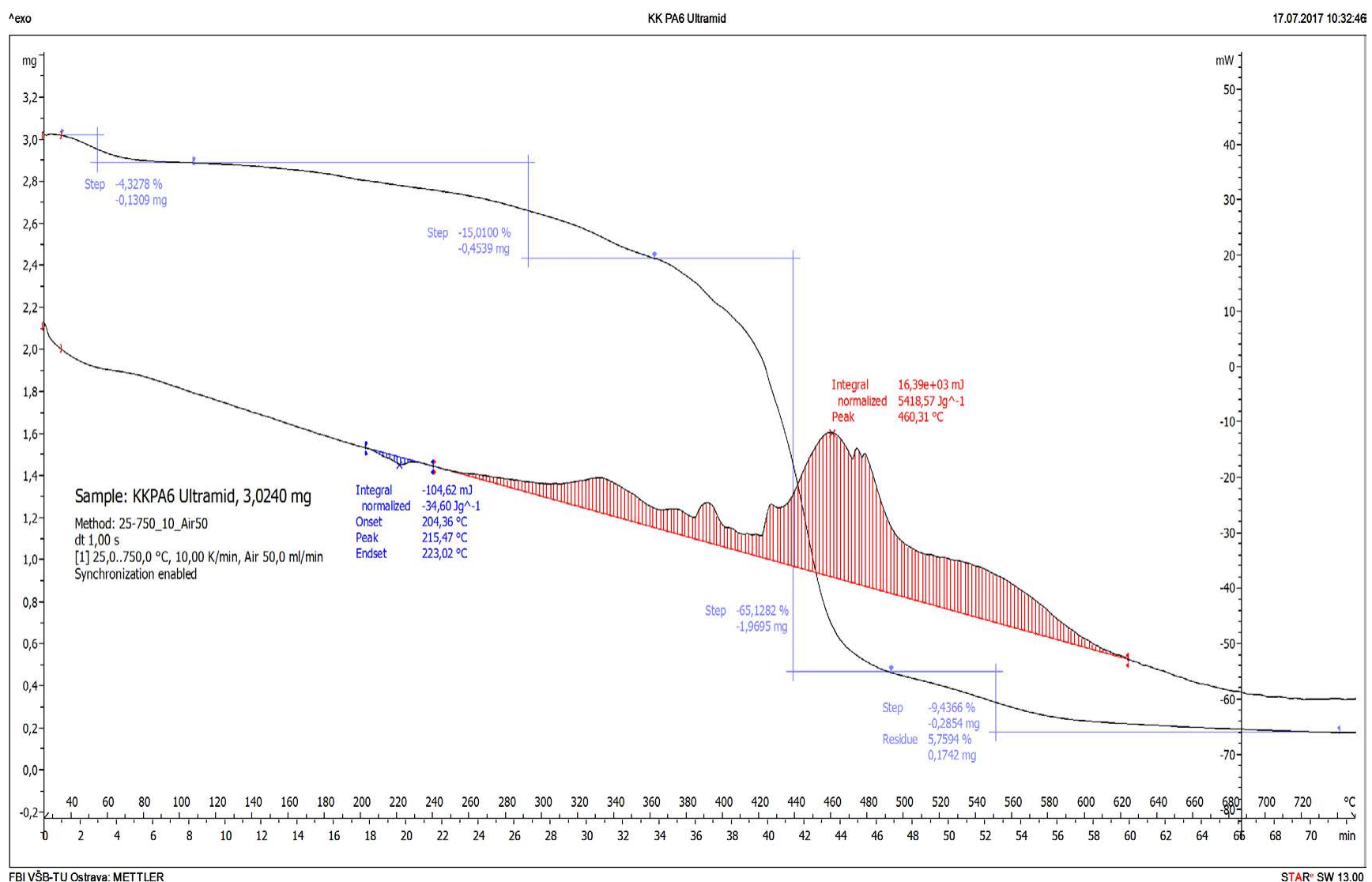

Figure 12: TGA and DSC analysis of PA6 (polyamide 6).

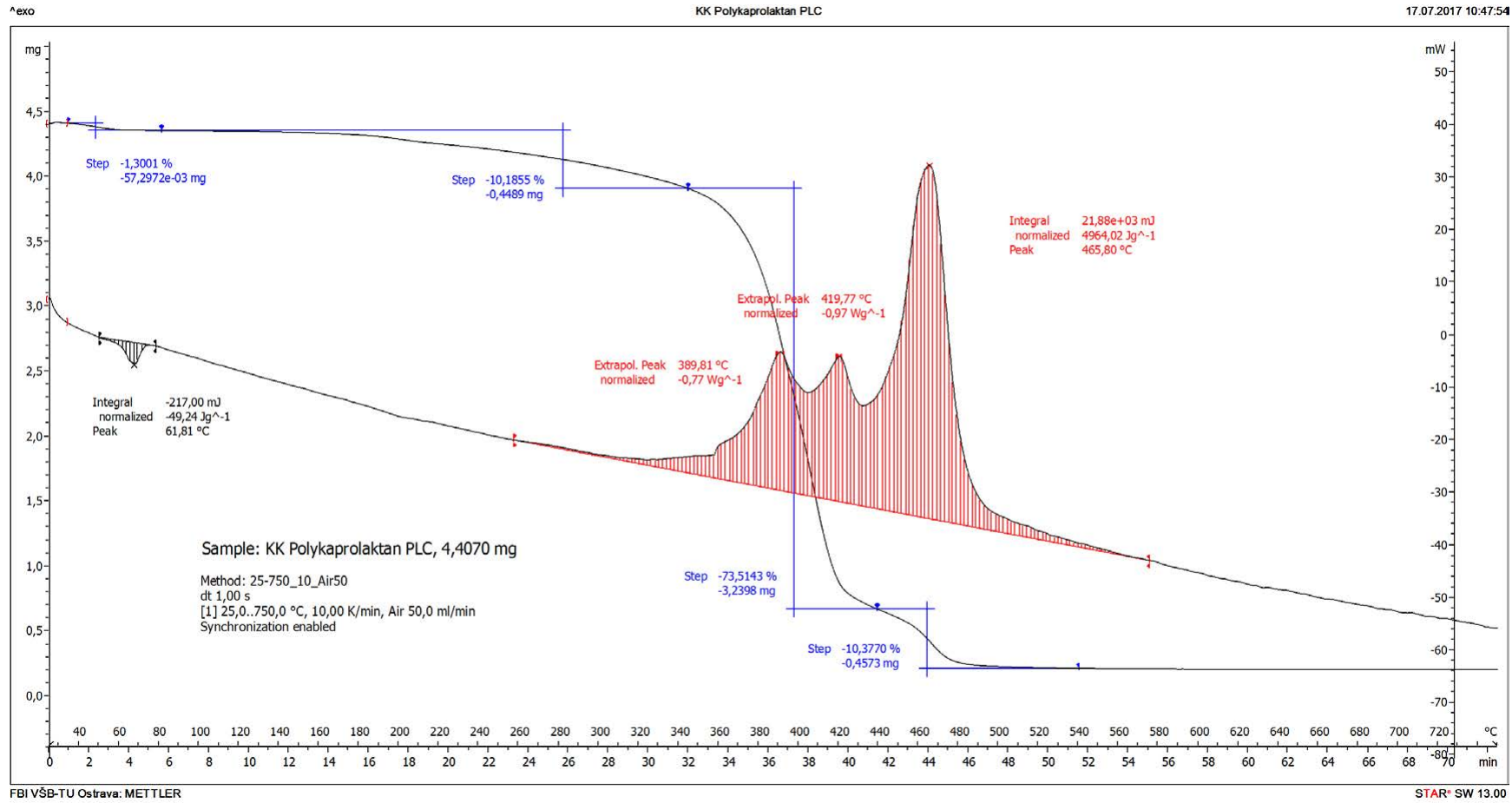

Figure 13: TGA and DSC analysis of PCL (polycaprolactone). 
of the sandwich decomposition. The first and the last exo-effect in the sandwich are affected by the GO decomposition exo-effect. Mutual influence of these components is obvious in the created sandwich arrangement from the comparison of shape and progression of the TGA and DSL curves for the sandwiches with GO and nano-textiles.

\section{Composite thermal analysis result comparison for GO- biochar/PCL/GO-biochar (II)}

The measurement thermograph (Figure 15) was divided into three blocks within the range of $254-630^{\circ} \mathrm{C}-\mathrm{b}$ ), c) and d) with continuous exo-thermal change. Block b) peaks at $268^{\circ} \mathrm{C}$, block c) ranges from 330 to $510^{\circ} \mathrm{C}$ with three hints of peaks and the high peak of the exo-effect was in block d) at $622^{\circ} \mathrm{C}$. The highest weight loss (58 \%) of the thermal decomposition has shown in block c).

The PCL decomposition itself happened in the thermal range of 260 $580^{\circ} \mathrm{C}$, with three identifiable exo-effects with maximums at $389^{\circ} \mathrm{C}$, $410^{\circ} \mathrm{C}$ and $465^{\circ} \mathrm{C}$. The main weight loss $(73 \%)$ happened between the first and the second exo-effect (Figure 13). The PCL influence in the composite had mainly manifested in the protracted c) block. The hybrid compound effect had also manifested in block b), c) and partially d). When comparing the TGA and DSC of the starting components and the prepared composite, increased thermal stability can be clearly declared for the composite with a difference of $160^{\circ} \mathrm{C}$, especially compared to the nano-textile.

Thermal analysis result comparison for the $\mathrm{go} / \mathrm{pcl} / \mathrm{go}$ (iii) composite and the caprolactam nano-textile

The measured thermograph was divided into three blocks in the temperature range of $150-600^{\circ} \mathrm{C}-\mathrm{b}$ ), c) and d), with mean temperature of $220^{\circ} \mathrm{C}$ for block b), temperature range of $265-480^{\circ} \mathrm{C}$ for block c), and mean temperature of $571^{\circ} \mathrm{C}$ for block d) (Figure 16).
The PCL decomposition itself happened in thermal range of $260-580^{\circ} \mathrm{C}$, with three identifiable exo-effects with maximums at $389^{\circ} \mathrm{C}, 419^{\circ} \mathrm{C}$ and $465^{\circ} \mathrm{C}$ (Figure 13). The main weight loss (73\%) happened between the first and the second exo-effect. The PCL influence in the composite had mainly manifested in the protracted c) block.

Thermal stability of the composite had increased by $100^{\circ} \mathrm{C}$ compared to the nano-textile (PCL) and the thermal change of the range for the last exo-effect. $30^{\circ} \mathrm{C}$ for the composite, $100^{\circ} \mathrm{C}$ for PCL, which is why we can expect mutual physical or chemical influence between the polymer and GO.

\section{Composite thermal analysis result comparison for $\mathrm{GO}_{-} \mathrm{TiO}_{2} /$ PCL/GO-TiO,}

The comparison of thermograph curves for the GO/PCL/GO composite alone and composite containing $\mathrm{TiO}_{2}$ has shown a difference in the thermal decomposition progression. The significant difference can be seen on the TGA curve in the last third of the decomposition (Figures 16-19). The decomposition of the $\mathrm{TiO}_{2}$ composite starts ca. $30^{\circ} \mathrm{C}$ later and the maximum of the last exo-effect was $70^{\circ} \mathrm{C}$ lower; despite that the thermal change of the decomposition reaction of this exo-effect had doubled.

It is obvious that the $\mathrm{TiO}_{2}$ content had played a part in the thermal properties of $\mathrm{GO}-\mathrm{TiO}_{2} / \mathrm{PCL} / \mathrm{GO}-\mathrm{TiO}_{2}$. According to literature [23] $\mathrm{TiO}_{2}$ is expected to be wrapped into plates of GO using hydroxy groups on the surface of GO leads to the Ti-O-C configuration.

\section{Meltblown technology}

A Meltblown technology was used to prepare a further type of sandwich arrangement between GO-Biochar and non-woven textiles. With this technology, polypropylene (PP) fabrics (Mostek) produced fiber

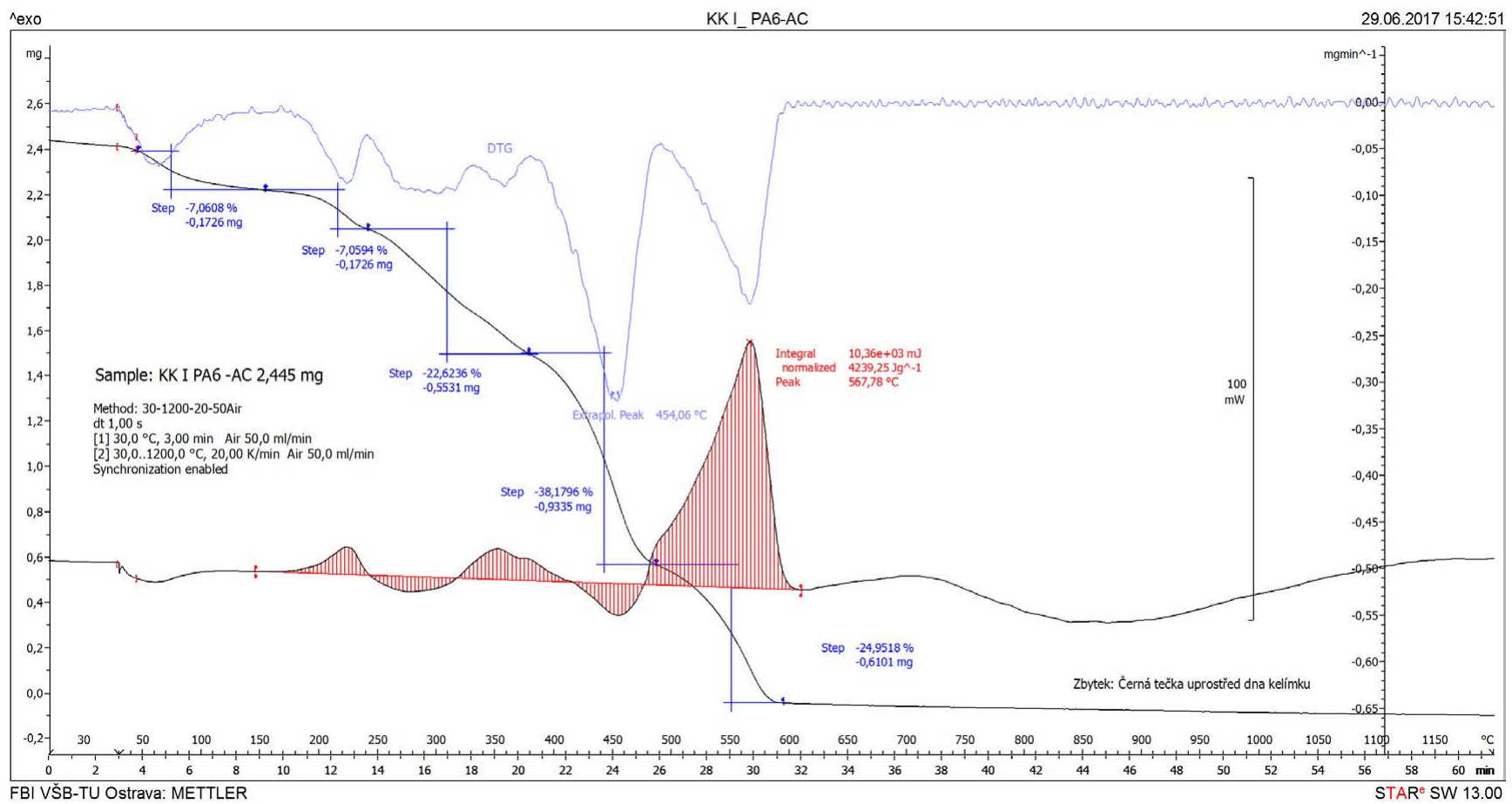

Figure 14: TGA and DSC analysis of product I (PA6/GO/PA6). 


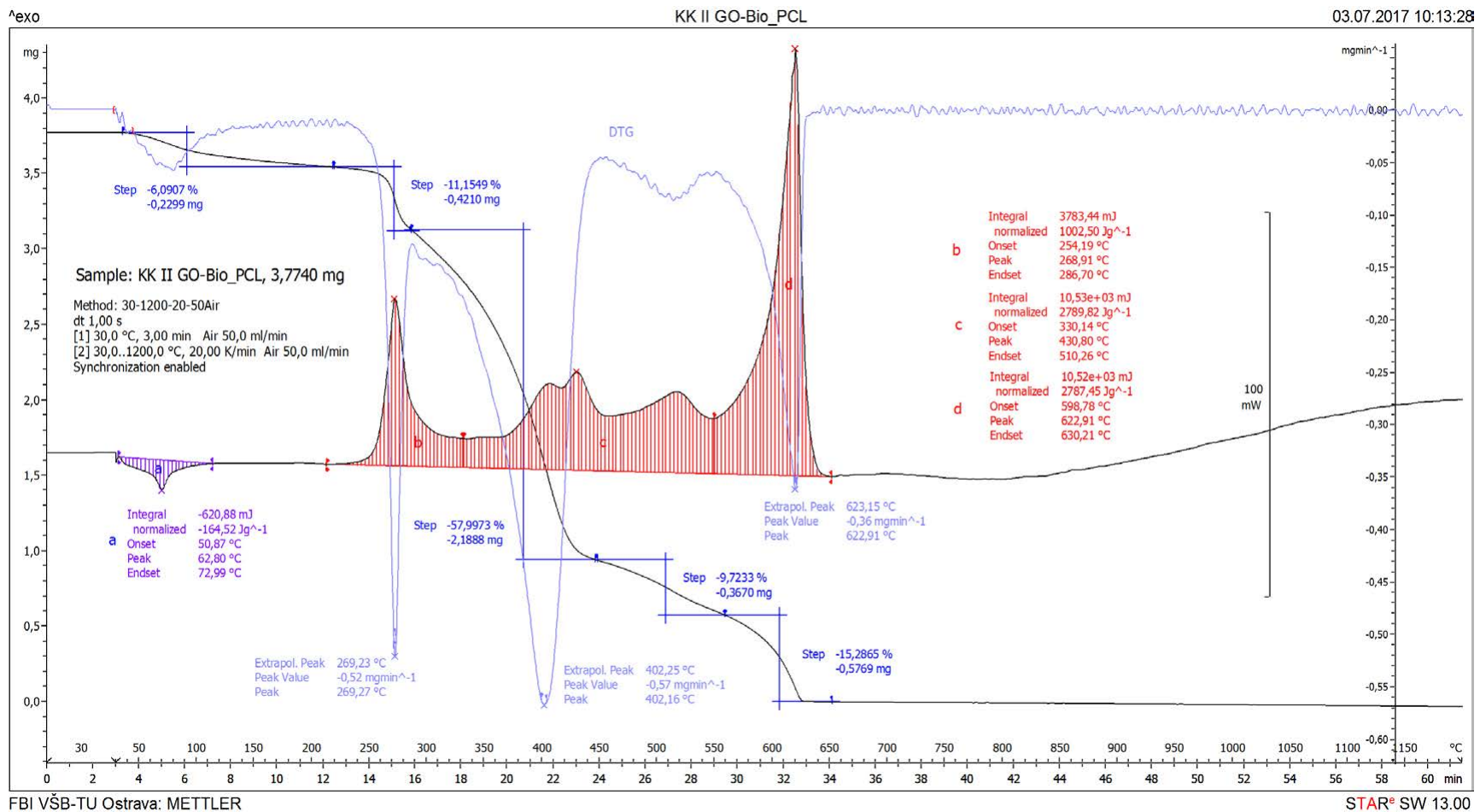

Figure 15: TGA and DSC analysis of product II (GO-biochar/PCL/GO-biochar).

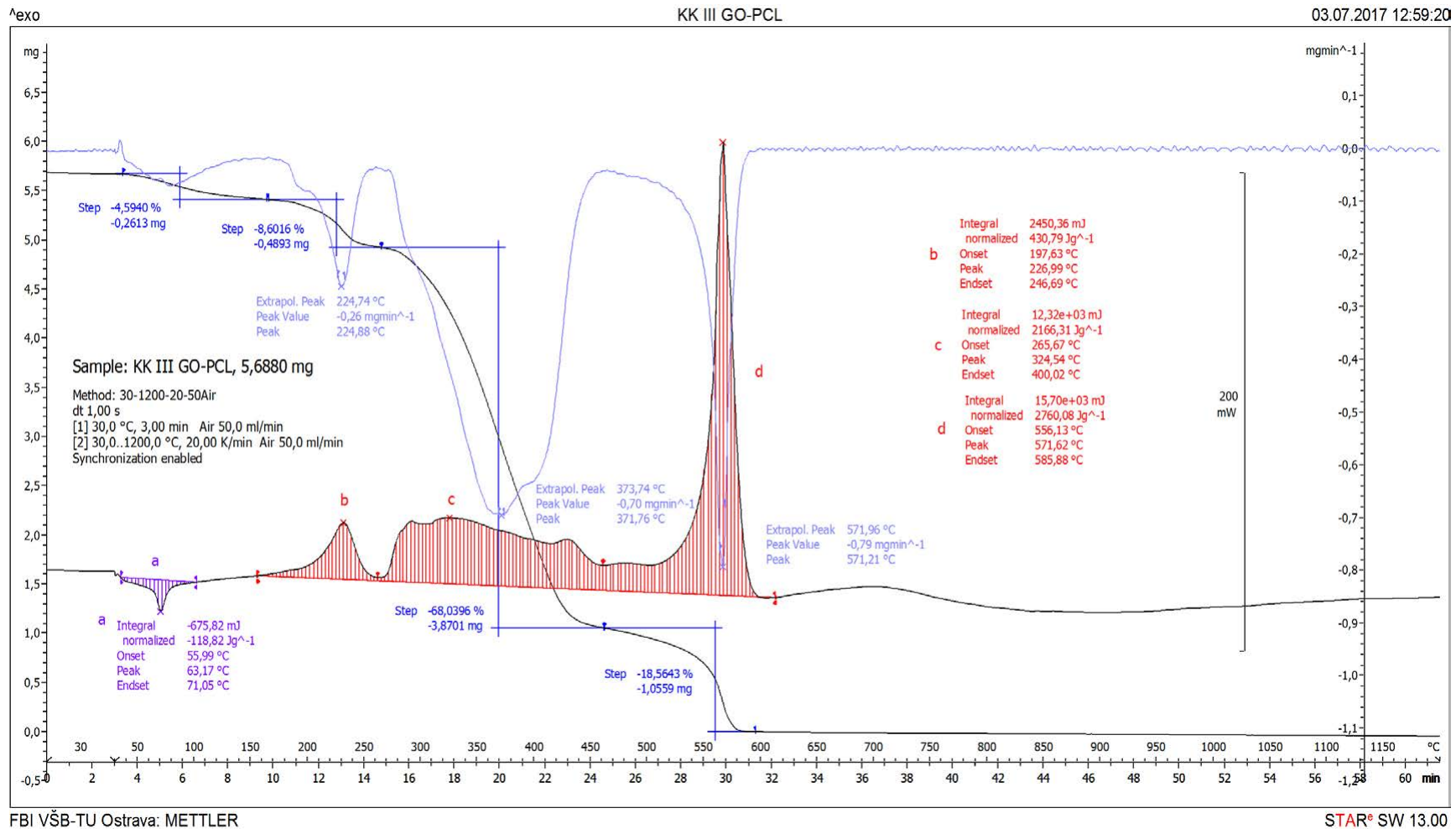

Figure 16: TGA and DSC analysis of product III (GO/PCL/GO) 
Citation: Roupcova P, Klouda K, Gembalova L, Kuzelova-Kostalova E, Chvojka J (2018) Laminated, Composite and Sandwich Membranes Based on Graphene-Oxide with Nano-Textiles. J Nanomed Nanotechnol 9: 517. doi: 10.4172/2157-7439.1000517

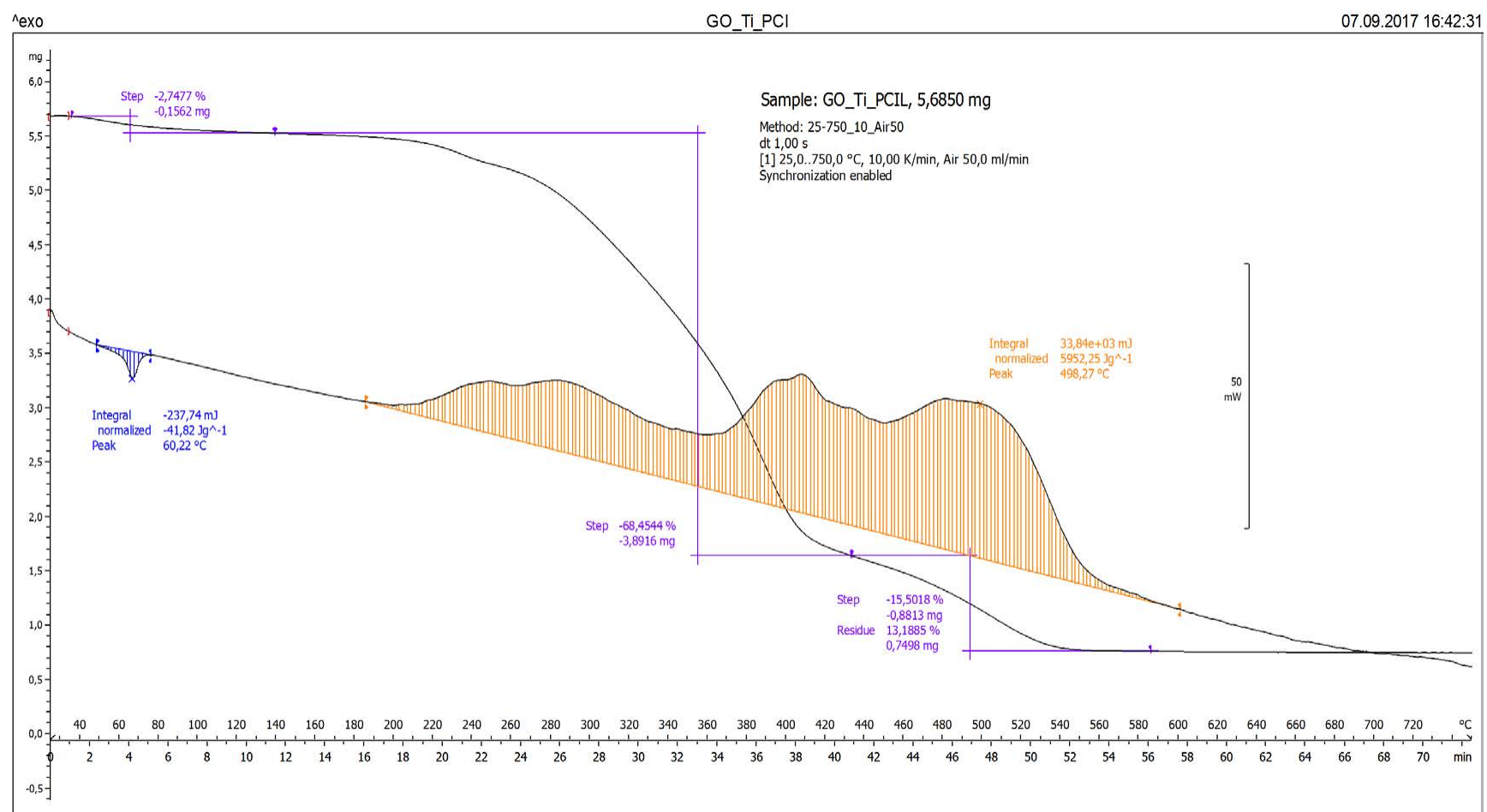

Figure 17: TGA and DSC analysis of product $\mathrm{GO}-\mathrm{TiO}_{2} / \mathrm{PCL} / \mathrm{GO}-\mathrm{TiO}_{2}$.

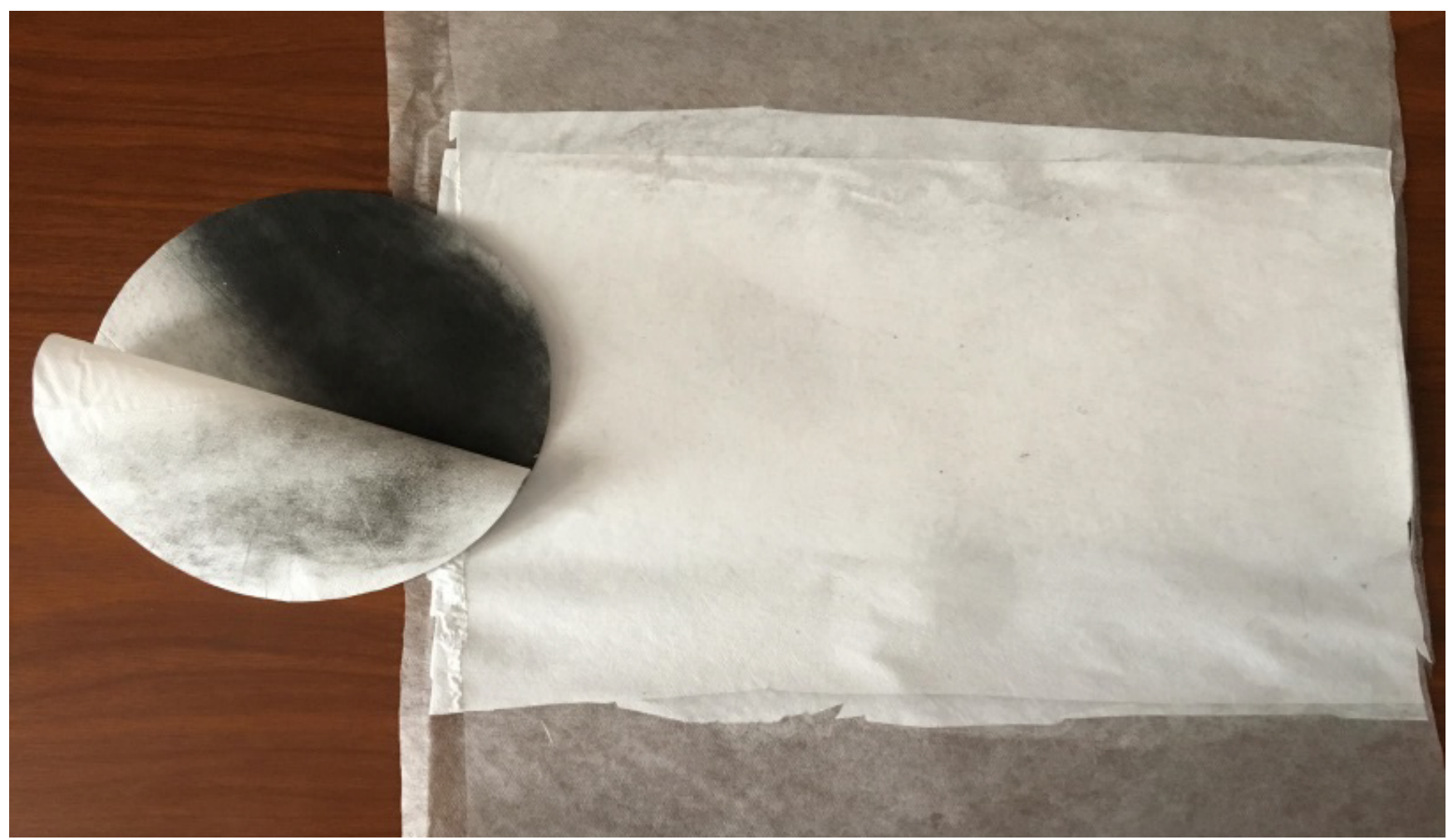

Figure 18: Prepared sandwich with biochar by Meltblown PP technology. 
Citation: Roupcova P, Klouda K, Gembalova L, Kuzelova-Kostalova E, Chvojka J (2018) Laminated, Composite and Sandwich Membranes Based on Graphene-Oxide with Nano-Textiles. J Nanomed Nanotechnol 9: 517. doi: 10.4172/2157-7439.1000517

Page 9 of 10

fabrics, which were doped with powder GO, GO-Biochar (2:1) and the biochemistry itself. Subsequently this deposited fabric was coated with nanoparticle with $\mathrm{PCl}$ and laminated (Figure 16) (where is shown cut out of the prepared foil by Meltblown technology on the left which was further tested).

This prepared material was tested according to Czech Technical Standart CSN EN 149: 2002 + A1: 20009 Respiratory protective devices on the cuts with adsorbent of the doped parts and parts without adsorbent.

\section{Specific measuring instruments:}

- INSPEC breathing resistance test device;

- Sheffield head;

- Manometer GDH 200-07;

- Yokogawa P052 Rotameter;

- Yokogawa P161 Rotameter;

- Stopwatch Ruhla;

- Thermometer type Centigrade 0.1;

- LORENZ type BIA paraffin oil aerosol filter device;

- Aerosol NaCl Testing Unit, MOORE'S Type 1100;

\section{Metrological provision}

The metrological provision of the instruments is performed in accordance with the Research Laboratory of Occupational health and Safety- metrology regulations (VÚBP-Praha).

\section{Test results of prepared membranes (Tables 1 and 2)}

$100 \%=\operatorname{ADF} 62$

$\mathrm{A}, \mathrm{B}=$ the samples with coating

$\mathrm{C}=\mathrm{A}$ sample without coating

160 -biochar

150 -GO-biochar

$200-\mathrm{GO}$

Best results against air resistance were achieved for the biochar membrane prepared by meltblown technology on non-woven fabrics from PP.

\section{Conclusion}

Products prepared using graphene oxide and its nano-textile hybrids (PCI, PA6) feature higher thermal stability than the default nanotextiles. Suspension consistence/ composition and nano-textile porousness can influence which connection is established and therefore which particular product is prepared. The mutual link and
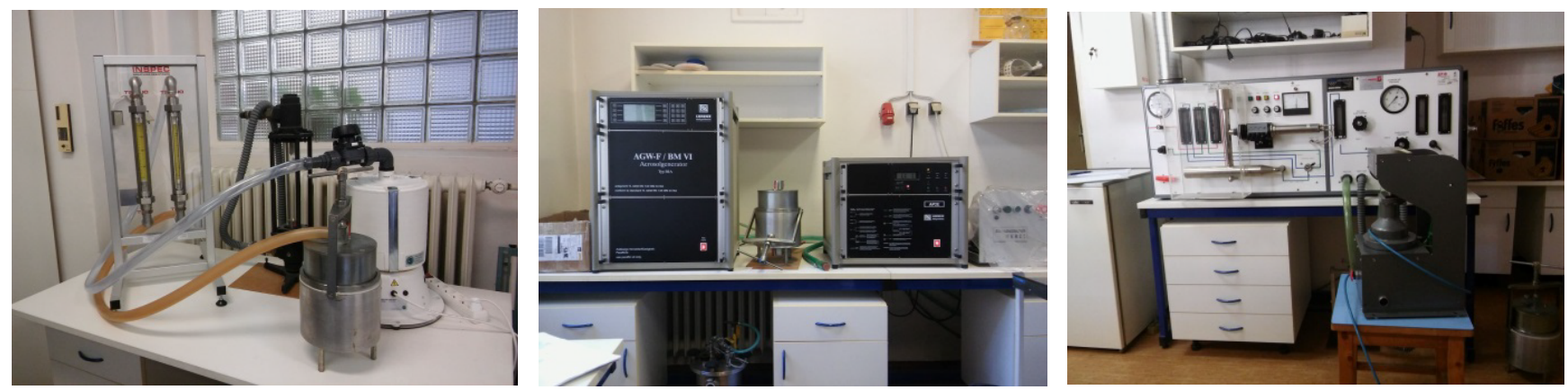

Figure 19: Measurement device for respiratory resistance and aerosol penetration for $\mathrm{NaCl}$ and paraffin oil (b) Sodium chloride test - Breakthrough of $\mathrm{NaCl}$ after 3 minutes. Flow rate $45 \mathrm{l} / \mathrm{min}$.

\begin{tabular}{|c|c|c|c|}
\hline \multirow{2}{*}{ Sample } & \multirow{2}{*}{ State } & \multicolumn{2}{|c|}{ Resistance in Pa } \\
\cline { 3 - 4 } & & During 30 I/min & During 95 l/min \\
\hline 200A-GO & AR & 1925 & - \\
\hline 200B-GO & AR & 1844 & 4920 \\
\hline 200C-GO & AR & 6.5 & 39 \\
\hline 160A-biochar & AR & 2230 & 3820 \\
\hline 160B-biochat & AR & 2150 & 3930 \\
\hline 160C-biochar & AR & 3 & 33 \\
\hline 150A-GO-biochar & AR & 1965 & 2710 \\
\hline 150B-GO-biochar & AR & 1971 & 2820 \\
\hline 150C-GO-biochar & AR & 4 & 35 \\
\hline
\end{tabular}

Note: Values 150,160 and 200 in the table and following table indicate the weight of the powder (adsorbent) per $\mathrm{m}^{2}$

Table 1: Determination of respiratory resistances.

\begin{tabular}{|c|c|c|}
\hline Sample & State & Penetration $\%$ \\
\hline 200B-GO & AR & $<1 \times 10^{-3}$ \\
\hline 200C-GO & AR & 98 \\
\hline 160B-biochar & AR & $<1 \times 10^{-3}$ \\
\hline 160C-biochar & AR & 96 \\
\hline 150B-GO-biochar & AR & $<1 \times 10^{-3}$ \\
\hline 150C-GO-biochar & AR & 99 \\
\hline
\end{tabular}

(a) Paraffin oil test - Breakthrough of paraffin oil after 3 minutes, flow rate $95 \mathrm{l} / \mathrm{min}$.

\begin{tabular}{|c|c|c|}
\hline Sample & State & Penetration \% \\
\hline 200A-GO & AR & 0 \\
\hline 200C-GO & AR & 93.1 \\
\hline 160A-biochar & AR & 0 \\
\hline 160C-biochar & AR & 93.1 \\
\hline 150A-GO-biochar & AR & 0 \\
\hline 150C-GO-biochar & AR & 96.5 \\
\hline
\end{tabular}

(b) Sodium chloride test - Breakthrough of $\mathrm{NaCl}$ after 3 minutes. Flow rate $45 \mathrm{I} / \mathrm{min}$

Table 2: Determination of aerosol penetration. 
Citation: Roupcova P, Klouda K, Gembalova L, Kuzelova-Kostalova E, Chvojka J (2018) Laminated, Composite and Sandwich Membranes Based on Graphene-Oxide with Nano-Textiles. J Nanomed Nanotechnol 9: 517. doi: 10.4172/2157-7439.1000517

combination of components, along with further graphene oxide modification, provide high application flexibility namely in electrical engineering as a membrane or sensor material, as well as adsorption or anti-bacterial material. Article shows the potential application of GO, Biochar and hybrid GO-Biochar with PP microfibers as an adsorptive material for the measurement of the respiratory resistance and aerosol penetration for certain substances $(\mathrm{NaCl}$, paraffin oil)

\section{References}

1. Huang $H$, Ying $Y$, Peng $X(2014)$ Graphene oxide nanosheet: an emerging star material for novel separation membranes. J Mat Che A 2: 13772-13782.

2. Zinadini S, Zinatizadeh AA, Rahimi M, Vatanpour V, Zangeneh H (2014) Preparation of a novel antifouling mixed matrix PES membrane by embedding graphene oxide nanoplates. J Memb Sci 453: 292-301.

3. Chae H, Lee J, Lee C, Kim I, Park P (2015) Graphene oxide-embedded thinfilm composite reverse osmosis membráně with high flux, anti-biofouling, and chlorine resistence. J Memb Sci 483: 128-135.

4. Hegab HM, Zou L (2015) Graphene oxide-assisted membranes: Fabrication and potential applications in desalination and water purification. J Memb Sci 484: 95-106.

5. Yoo BM, Shin HJ, Yoon HW, Park HB (2013) Graphene and Graphene Oxide and Their Uses in Barrier Polymers. Inc J Appl Polym Sci 131: 39628-39650.

6. Fatemi SM, Abbasi Z, Rajabzadeh H, Hashemizadeh SA, Deldar AN (2017) A review of recent advances in molecular simulation of graphene-derived membranes for gas separation. Springer 71: 194.

7. Akbari A, Sheath P, Martin ST, Shinde DB, Shaibani M, et al. (2016) Largearea graphene-based nanofiltration membranes by shear alignment of discotic nematic liquid crystals of graphene oxide. Nat Commu.

8. https://pubs.acs.org/doi/abs/10.1021/acsnano.5b07304

9. Woo YC, Tijing LD, Shim WG, Choi JS, Kim SH, et al. (2016) Water desalination using graphene-enhanced electrospun nanofiber membrane via air gap membrane distillation. J Memb Sci 520: 99-110.
10. Huang L, Zhang M, Li C, Shi G (2015) Graphene-Based Membranes for Molecular Separation. J Phys Chem Lett 6: 2806-2815.

11. You Y, Sahajwalla V, Yoshimura M, Joshi RK (2016) Graphene and graphene oxide for desalination. Nanoscale 8: 117-119.

12. Dervin S, Dionysiou DD, Pillai SC (2016) 2D nanostructures for water purification: graphene and beyond. Nanoscale 8: 15115-15131.

13. Aghigh A, Alizadeh V, Wong HY, Islam S, Amin N, et al. (2015) Recent advances in utilization of graphene for filtration and desalination of water: $A$ review. Desalination 365: 386-397.

14. Han Y, Xu Z, Gao C (2013) Ultrathin Graphene Nanofiltration Membrane for Water Purification. Adv Func Mat 23: 3693-3700.

15. Lawler J (2016) Incorporation of Graphene-Related Carbon Nanosheets in Membrane Fabrication for Water Treatment: A Review. Membranes 4: 57.

16. Jiao S, Xu Z (2015) Selective Gas Diffusion in Graphene Oxides Membranes: A Molecular Dynamics Simulations Study. ACS Appl Mater Interfaces 7: 9052 9059 .

17. Tanugi DC, Grossman JC (2012) Water Desalination across Nanoporous Graphene. Nano Lett 12: 3602-3608.

18. Kim D, Kim DW, Lim HK (2014) Intercalation of Gas Molecules in Graphene Oxide Interlayer: The Role of Water. J Phy Chem C 118: 11142-11148.

19. Sun C, Wen B, Bai B (2015) Application of nanoporous graphene membranes in natural gas processing: Molecular simulations of $\mathrm{CH}_{4} / \mathrm{CO}_{2}, \mathrm{CH}_{4} / \mathrm{H}_{2} \mathrm{~S}$ and $\mathrm{CH}_{4} / \mathrm{N}_{2}$ separation. Che Eng Sci 138: 616-621.

20. Kim HW, Yoon HW, Yoon SM, Yoo BM, Yoo BM (2003) Selective Gas Transport Through Few-Layered Graphene and Graphene Oxide Membranes. Science 342: 91-95

21. Fatemi FS, Arabieh M, Sepehrian H (2015) Nanoporous graphene oxide membrane and its application in molecular sieving. Carbon lett 16: 183-191.

22. Mahmood FS, Hamid S, Masoud A (2016) Selective Nanopores in Graphene Sheet for Separation I-129 Isotope from Air. J Adv Phy 5: 1-8.

23. Chao C, Ci W, Long M, Zhou B, Wu Y, et al. (2010) Synthesis of Visible-light Responsive Graphene oxide/TiO2 Composites with p/n Heterojunction. ACS Nano 4: 6425-6432. 